\title{
A unusual cause of large bowel obstruction: to keep an open mind, a case report
}

Tuhin Shah ${ }^{1}$ and Arjana Shakya ${ }^{1}$

${ }^{1}$ Asia Pacific Medical College

April 28, 2020

\begin{abstract}
Enterolithiasis or formation of gastrointestinal concretions is an uncommon medical condition that develops in the setting of intestinal stasis due to various pathologies. Its prevalence ranges upto $10 \%$ and can present in different clinical picture to challenge a clinician.
\end{abstract}

A unusual cause of large bowel obstruction: to keep an open mind, a case report

Tuhin Shah, Arjana Shakya

Tuhin Shah

Department of Surgery

Asia Pacific Medical College

Birgunj, Nepal

Arjana Shakya

Department of Ophthalmology

Asia Pacific Medical College

Birgunj, Nepal

Corresponding Author:

Tuhin Shah

dr.tuhinshah@gmail.com

Key clinical message:

Enterolithiasis or formation of gastrointestinal concretions is an uncommon medical condition that develops in the setting of intestinal stasis due to various pathologies. Its prevalence ranges upto $10 \%$ and can present in different clinical picture to challenge a clinician.

\section{Question:}

A 60 year lady presented with features of large bowel obstruction to the emergency room. She was admitted twice before with features of subacute bowel obstruction at another center but was managed conservatively. Her blood reports showed leucocytosis while the rest was normal. Her abdominal X-ray showed few dilated ileal loops with multiple air fluid levels. Unusual finding on X-ray was the presence of enteroliths on the right lumbar and hypochondriac region. What do you suggest should be the management? 
1. Conservative management

2. Laparotomy and extraction of the enteroliths alone

3. Colonoscopy

4. Exploratory laparotomy with bowel resection without cholecystectomy

5. Exploratory laparotomy with bowel resection with cholecystectomy

Here in our case we had to do an exploratory laparotomy with right hemicolectomy and cholecystectomy. As it was a case of gall stone ileus with stricture in the ascending colon suspicious of underlying pathology. (Figure 1)

Enteroliths are classified as primary enteroliths -which are formed within the gastrointestinal tract or secondary enteroliths, stones which form outside the bowel and migrate to the intestine, ${ }^{1}$ of which the most common type is gallstones. Optimal treatment of enterolithiasis should focus on enterolith removal and correction of underlying pathology to prevent future formation of additional enteroliths. ${ }^{2}$

\section{Author Contribution Statement:}

Tuhin Shah: study conception and design; acquisition of data; analyzed and interpreted the data; drafted the manuscript

Arjana Shakya: drafted the manuscript and performed critical analysis.

\section{References:}

1. Grettve S. A contribution to the knowledge of primary true concrements in the small bowel. Acta Chir Scand 1947

2. Gurvits GE, Lan G. Enterolithiasis. World J Gastroenterol 2014; 20(47): 17819-17829

\section{Hosted file}

enteroliths-png. 1 available at https ://authorea. com/users/309597/articles/441293-a-unusual-causeof-large-bowel-obstruction-to-keep-an-open-mind-a-case-report 